2013s-27

\title{
Social Networks and Peer Effects at Work
}

\author{
Julie Beugnot, Bernard Fortin, Guy Lacroix, \\ Marie Claire Villeval
}

Série Scientifique
Scientific Series

\section{Montréal \\ Août 2013}

(C) 2013 Julie Beugnot, Bernard Fortin, Guy Lacroix, Marie Claire Villeval s. Tous droits réservés. All rights reserved. Reproduction partielle permise avec citation du document source, incluant la notice $($ ).

Short sections may be quoted without explicit permission, if full credit, including (C) notice, is given to the source.
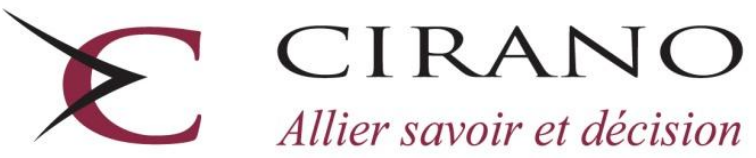

Allier savoir et décision

Centre interuniversitaire de recherche en analyse des organisations 


\section{CIRANO}

Le CIRANO est un organisme sans but lucratif constitué en vertu de la Loi des compagnies du Québec. Le financement de son infrastructure et de ses activités de recherche provient des cotisations de ses organisations-membres, d'une subvention d'infrastructure du Ministère du Développement économique et régional et de la Recherche, de même que des subventions et mandats obtenus par ses équipes de recherche.

CIRANO is a private non-profit organization incorporated under the Québec Companies Act. Its infrastructure and research activities are funded through fees paid by member organizations, an infrastructure grant from the Ministère du Développement économique et régional et de la Recherche, and grants and research mandates obtained by its research teams.

\section{Les partenaires du CIRANO}

\section{Partenaire majeur}

Ministère de l'Enseignement supérieur, de la Recherche, de la Science et de la Technologie

Partenaires corporatifs

Autorité des marchés financiers

Banque de développement du Canada

Banque du Canada

Banque Laurentienne du Canada

Banque Nationale du Canada

Banque Scotia

Bell Canada

BMO Groupe financier

Caisse de dépôt et placement du Québec

Fédération des caisses Desjardins du Québec

Financière Sun Life, Québec

Gaz Métro

Hydro-Québec

Industrie Canada

Investissements PSP

Ministère des Finances et de l'Économie

Power Corporation du Canada

Rio Tinto Alcan

State Street Global Advisors

Transat A.T.

Ville de Montréal

\section{Partenaires universitaires}

École Polytechnique de Montréal

École de technologie supérieure (ÉTS)

HEC Montréal

Institut national de la recherche scientifique (INRS)

McGill University

Université Concordia

Université de Montréal

Université de Sherbrooke

Université du Québec

Université du Québec à Montréal

Université Laval

Le CIRANO collabore avec de nombreux centres et chaires de recherche universitaires dont on peut consulter la liste sur son site web.

Les cahiers de la série scientifique (CS) visent à rendre accessibles des résultats de recherche effectuée au CIRANO afin de susciter échanges et commentaires. Ces cahiers sont écrits dans le style des publications scientifiques. Les idées et les opinions émises sont sous l'unique responsabilité des auteurs et ne représentent pas nécessairement les positions du CIRANO ou de ses partenaires.

This paper presents research carried out at CIRANO and aims at encouraging discussion and comment. The observations and viewpoints expressed are the sole responsibility of the authors. They do not necessarily represent positions of CIRANO or its partners. 


\title{
Social Networks and Peer Effects at Work ${ }^{*}$
}

\author{
Julie Beugnot $^{\dagger}$, Bernard Fortin ${ }^{*}$, Guy Lacroix ${ }^{\S}$, Marie Claire Villeval $^{* *}$
}

\begin{abstract}
Résumé / Abstract
This paper extends the standard work effort model by allowing workers to interact through networks. We investigate experimentally whether peer performances and peer contextual effects influence individual performances. Two types of network are considered. Participants in Recursive networks are paired with participants who played previously in isolation. In Simultaneous networks, participants interact in real-time along an undirected line. Mean peer effects are identified in both cases. Individual performances increase with peer performances in the recursive network. In the simultaneous network, endogenous peer effects vary according to gender: they are large for men but not statistically different from zero for women.
\end{abstract}

Mots clés/key words : Peer effects, social networks, work effort, piece rate, experiment.

Codes JEL : C91, J16, J24, J31, M52

\footnotetext{
* The authors thank C. Bellemare, L. Bissonnette, Y. Bramoullé, M. Comola, D. Cooper, R. Dieye, C. Eckel, D. Margolis, N. Jacquemet, and T. Salmon for useful discussions and comments. They also thank participants at the Florence Workshop on Behavioural and Experimental Economics, at the European Workshop on Experimental and Behavioural Economics in Frankfurt, at seminars at UT Dallas, Southern Methodist University in Dallas, Texas A\&M University, Florida State University, Nanyang Technology University in Singapore, Erasmus University in Rotterdam, University of Padova, University of Paris I, IZA Worshop on Behavioral Organizational Economics in Bonn, World Meeting of the Economic Science Association in Zurich, and GATE. They are grateful to N. Viennot and R. Cautain for programming the experiment, and to Z. Dai for research assistance. Financial support from the French National Research Agency (ANR-09-BLAN-0321, "MINT" project) is gratefully acknowledged. This research was conducted within the framework of the LABEX CORTEX (ANR-11-LABX-0042) of Université de Lyon, within the "Investissements d'Avenir" (ANR-11IDEX-007) operated by the French National Research Agency (ANR).

† Department of economics, Université Laval, CIRPÉE, email : Julie.Beugnot@ecn.ulaval.ca.

\$Department of economics, Université Laval, CIRPÉE and CIRANO, email: Bernard.Fortin@ecn.ulaval.ca.,

$\S$ Department of economics, Université Laval, CIRPÉE and CIRANO, email : guy.lacroix@ecn.ulaval.ca.

*** University of Lyon, France; GATE, CNRS, email: villeval@ gate.cnrs.fr.
} 


\section{Introduction}

Everyday life offers many examples whereby individual labor supply and performance not only depend on individual wage and characteristics but also on the wage and performance of other workers within one's reference group. For peer effects to arise, a worker must directly observe his co-workers' performance or the latter must be made known to him. Since Kandel and Lazear (1992)'s seminal theoretical contribution, several empirical studies have found positive peer effects in settings as varied as tournaments, piece-rate (Azmat and Iriberri, 2010; Blanes i Vidal and Nossol, 2011) and fixed compensation schemes (Falk and Ichino, 2006; Mas and Moretti, 2009). ${ }^{1}$ Concern for conformity, competitiveness, monitoring or any combination thereof are potential candidates to explain the relationship between individual and peer performances. ${ }^{2}$ Other studies, however, have found a relatively weak positive link (Guryan et al., 2009; Bellemare et al., 2010), while still others have even found peer effects to adversely impact the lowest-performing employees (Barankay, 2012) and disappointment-averse workers (Gill and Prowse, 2012).

Most studies assume individuals interact in groups 3 (save for Mas and Moretti (2009) who study peer effects within a so-called directed network). This raises concern given the pervasiveness of social networks (Jackson, 2010, 2011) in which each person may have his own reference group. Yet, while peer effects within social networks have been studied in various fields of inquiry ${ }^{4}$, their analysis on labor markets has been limited to the transmis-

\footnotetext{
${ }^{1}$ In the experiment by Falk and Ichino (2006), participants had to wrap envelopes either alone in a room or alongside a co-worker. Working in pair induced a higher output level and a lower within-pair variance. Mas and Moretti (2009) investigate peer effects on cashiers' productivity with data from a large grocery chain. The study does not focus on social networks per se but uses the spatial distribution of workers and the amount of time they have previously spent working together to proxy peer effects.

${ }^{2}$ It has also been shown that outperforming others is associated with an activation of the neural circuitry involved in the processing of rewards in the brain (Dohmen et al., 2011).

${ }^{3}$ This means that individuals are affected by all others in their group and by none outside of it.

${ }^{4}$ See Bertrand et al. (2000) on welfare participation, De Weerdt and Dercon (2006) on the provision of informal health insurance in developing countries, Munshi (2010) on labor and credit networks on economic activity in developing countries, Karlan et al. (2009) on risk-sharing, Calvó-Armengol et al. (2009) on education, Patacchini and Zenou (2008) on criminal activity, Cassar (2007) on coordination and cooperation, and Chen et al. (2010) on contributions to on-line communities.
} 
sion of information about job opportunities (Laschever, 2011; Calvó-Armengol et al., 2009) and the role of referrals (Topa, 2011). The role of social networks on work effort has been largely ignored ${ }^{5}$ and our paper partly aims at filling this gap.

Empirical studies of peer effects generally rely upon a linear-in-means model (see Blume et al., 2011). These studies linearly relate individual outcome to own characteristics and reference group mean outcome (endogenous peer effects) and mean characteristics (contextual peer effects). However, it is well known since Manski (1993)'s seminal paper that this model is plagued with two identification problems. The first relates to the difficulty of distinguishing the endogenous peer effects from spurious correlated effects caused by self-selection in peer groups (e.g., homophily) or common shocks. The second concerns distinguishing between endogenous peer effects and contextual effects due to the simultaneity of individual decisions, even assuming away correlated effects. Thus, when individuals interact in groups that include themselves, the simultaneous decision making introduces a perfect collinearity between the mean outcome of each group and its mean characteristics. Manski (1993) refers to the identification problem as the "reflection problem".

Correlated effects can be overcome by means of random group assignment. Sacerdote (2001) analyzes peer effects in student outcomes using information on roommates who were randomly assigned to dorms. ${ }^{6}$ In the absence of correlated effects, several approaches have been proposed to solve the reflection problem. First, group interactions that exclude oneself can identify both the endogenous and the contextual effects if there is sufficient group size variation (Lee, 2007). Second, non-linearities in social interactions (Brock and Durlauf, 2001; Fortin et al., 2007; Grodner et al., 2010) as well as recursive interactions

\footnotetext{
${ }^{5}$ Exceptions are Bandiera et al. $(2005,2009,2010)$ who use field experiments to investigate the role of social connections on productivity. They show how friendship affects the impact of various incentive schemes on worker productivity. Yet friendship at work is a special form of social networks. Spatial arrangements in the workplace provide a large array of networks within which workers in a given vicinity, who may or may not be friends, can observe their respective productivity.

${ }^{6}$ Stinebrickner and Stinebrickner (2006) argue, however that such assignment may make the reference group irrelevant, or partially observed, thus underestimating the true peer effect.
} 
(Bellemare et al., 2010) have been shown to ease identification. Finally, identification obtains under quite general conditions when interactions are structured through social networks (Bramoullé et al., 2009 (henceforth BDF); Goldsmith-Pinkham and Imbens, 2012).

Group size variation, exogenous team formation, etc. are all clever workarounds that have been used to identify peer effects. In this paper the empirical analysis is based upon data obtained from a laboratory experiment involving real-effort tasks under a piece-rate scheme. The laboratory setting was chosen for a number of reasons. First, by randomly assigning participants to various sessions, we avoid the issue of correlated effects. Likewise, random assignment across networks ensures knowledge of the true reference group. In addition, individual observable characteristics and performance as well as those of the members of the reference group are perfectly known, as required by the linear-in-means model. Finally, we can afford to experiment with various types of interactions. In particular, we have chosen to experiment with two types of interactions: recursive and simultaneous. By recursive interactions, we refer to a setup in which participants in a given session are matched to participants who have played in isolation in a previous session. Simultaneous interactions occur when participants interact in real-time. In both cases, participants interact within specific network structures.

Assuming the Recursive and the Simultaneous treatments have the same informational content, they should yield the same peer effects estimate for two reasons. First, the linearin-means model is robust to network structures. Second, the mean peer performance is exogenous in the Recursive treatment while the network structure intrinsically generates powerful instruments that can be used to correct for its endogeneity in the Simultaneous treatment. Consequently, any discrepancy between the two estimates can only result from informational differences in the treatments.

Our findings indicate that participants in the Recursive treatment respond positively to their own piece rate as well as to their peers' mean performance. Interestingly, males are more responsive than females both to their own piece rate and to their peers' perfor- 
mance. However, in the Simultaneous treatment, the peer effect is gender specific. Men respond very strongly to their peers' performance whereas women are totally unaffected by their peers' behavior. The implications of these results are twofold. First, recursive and simultaneous interactions are distinct treatments, that is, they constitute distinct informational environments despite using the same monetary incentives. Learning about your colleagues' output on the assembly line in the previous work shift, and being told about their performance in real time does not induce the same response. Second, conformism and competitiveness in the workplace seems to matter considerably more for men. These results are consistent with some previous literature that has shown that contrary to men, whose

performance is enhanced by competitive monetary incentives, women tend to shy away from competition (Gneezy et al., 2003; Niederle and Vesterlund, 2007). Our results suggest that these differences also hold for non monetary, informational, incentives. Simultaneous information on peer performances thus reinforces the impact of monetary incentives only on more competitive (male) workers.

The remainder of the paper is structured as follows. Sections 2 presents a theoretical model of peer effects at work. Section 3 describes the experimental design and procedures. Section 4 presents our econometric strategy and discusses the results. Section 5 concludes.

\section{Theory}

In this paper we purposefully design a specific social network to identify peers' performance and contextual effects. The information flows between members follow a particular pattern. Membership to a given network is randomized to avoid issues of endogeneity in network formation. Our contention is that social networks offer a powerful means by which peer effects can be identified in a statistically efficient manner.

\subsection{Baseline treatment}

Individual interactions within a social network need not occur simultaneously. Information concerning peer behavior may be predetermined in some sense. For example, workers 
on an assembly line may learn about the output level of their peers in a previous work shift. In other cases, individuals do interact simultaneously. A salesperson may learn about the sales figures of his peers in real time as is often the case with pharmaceutical representatives. For our purpose, we need to design different treatments to accommodate these possibilities. We begin by defining the Baseline treatment that will be used to form pairs in the Recursive treatment.

Each treatment includes $s$ sessions indexed by $l$, with $i=1, \ldots, n_{l}$ participants who play a total of $t=1, \ldots, T_{l}$ periods. To simplify the notation, we assume there is a single session per treatment (with $n_{l}=n$ and $T_{l}=T$ ). Total work time per period is fixed and allocated between on-the-job leisure and work (or effort). Effort is proxied by individual production per period. ${ }^{7}$ Individuals are isolated, that is, they choose their effort without knowledge about other participants' production or characteristics. Individuals are paid a piece-rate for each unit of production.

Finally, we assume preferences for consumption and on-the-job leisure can be represented by a utility function that rationalizes the semi-log effort function (see Heckman, 1974) when maximized under the budget and time constraints :

$$
e_{i t}=\alpha+\alpha_{1} w_{i t}+\boldsymbol{\alpha}_{2}^{\prime} \boldsymbol{z}_{i t}+\varepsilon_{i t} \quad \text { with } E\left[\varepsilon_{i t} \mid \boldsymbol{X}_{i}\right]=0
$$

where $e_{i t}$ is individual's $i$ effort at period $t, w_{i t}$ is his piece-rate wage (in log), $\boldsymbol{z}_{i t}$ is a vector of observable characteristics, ${ }^{8} \varepsilon_{i t}$ is a random term and $\boldsymbol{X}_{i}$ denotes the matrix of explanatory

\footnotetext{
${ }^{7}$ In principle, we could specify a production function relating output to work effort, other inputs and unobservable shocks. However, it would be difficult to identify technology from preferences in the model. Thus, following Dickinson (1999), we simply assume that work effort is proxied by output.

${ }^{8}$ To derive the indirect utility function associated with the determinist part of (1), denote $m_{i}$ the individual $i$ 's nonwage income (e.g., his show-up fee), and define $w_{i t}=\log \omega_{i t}, \boldsymbol{\alpha}_{2}^{\prime}=\left(\alpha_{2}, \boldsymbol{\alpha}_{2}^{-\prime}\right)$ and $\boldsymbol{z}_{i t}=\left(m, \boldsymbol{z}_{i t}^{-\prime}\right)^{\prime}$. Integrating Roy identity, one shows (see Stern 1986, pp.177-78) that the indirect utility function is:

$$
v\left(\omega_{i t}, m_{i} ; \boldsymbol{z}_{i t}^{-}\right)=\frac{\exp \left(\alpha_{2} \omega_{i t}\right)}{\alpha_{2}}\left(\alpha+\alpha_{1} \log \omega_{i t}+\alpha_{2} m_{i}+\boldsymbol{\alpha}_{2}^{-\prime} \boldsymbol{z}_{i t}^{-}\right)-\frac{\alpha_{1}}{\alpha_{2}} E i\left(\alpha_{2} \omega_{i t}\right),
$$

where $\operatorname{Ei}(x)$ is the standard exponential integral $\int_{-\infty}^{x} \exp (a) / a d a$. Slutsky's condition, $\alpha_{1} \geq \alpha_{2} \omega_{i t} e_{i t}$, is assumed to hold.
} 
variables for all periods, that is, $\boldsymbol{X}_{i}=\left(\boldsymbol{w}_{i}, \boldsymbol{Z}_{i}\right)$. As written, all the explanatory variables are assumed strictly exogenous. ${ }^{9}$

\subsection{Recursive treatment}

Participants in the Recursive treatment are each associated with a specific reference group, $N_{i}$, that comprises $n_{i}$ isolated individuals drawn from the Baseline treatment. They are informed about the average effort and wage as well as the mean characteristics of their reference group. The information flow is thus unidirectional and may influence production levels through imitation, conformism, or competition. Social interactions is introduced in the model by assuming that the utility function has two additively separable components: an individual sub-utility function à la Stern (1986) and a social sub-utility function. The arguments of the latter include consumption, leisure and information about the reference group. We assume that maximization of this utility function with respect to consumption and leisure under the budget and time constraints yields the following work effort function: ${ }^{10}$

$$
e_{i t}=\beta+\beta_{1} w_{i t}+\boldsymbol{\beta}_{2}^{\prime} \boldsymbol{z}_{i t}+\beta_{3} \frac{1}{n_{i}} \sum_{j \in N_{i}} e_{j t}+\beta_{4} \frac{1}{n_{i}} \sum_{j \in N_{i}} w_{j t}+\boldsymbol{\beta}_{5}^{\prime} \frac{1}{n_{i}} \sum_{j \in N_{i}} \boldsymbol{z}_{j t}+\varepsilon_{i t}
$$

Comparing equations (1) and (2) shows that peer performance and contextual effects are implicitly captured by the intercept in the Baseline treatment. Equation (2) thus corresponds

\footnotetext{
${ }^{9}$ In the general case we allow for session fixed effect (for $l=1, \ldots, s$ ). These may possibly be correlated with the explanatory variables and aim at capturing a changing laboratory environment (weather, daytime etc.). Conditional on $\alpha_{l}$, though, the explanatory variables are assumed to be strictly exogenous. This framework includes the likely case where the session effects are random and uncorrelated with the explanatory variables.

${ }^{10}$ The indirect utility function associated with this recursive semi log work effort function is:

$$
\begin{aligned}
v\left(\omega_{i t}, m_{i}, \boldsymbol{z}_{i t}^{-}, \boldsymbol{e}_{j t}, \boldsymbol{\omega}_{j t}, \boldsymbol{z}_{j t}\right) & =\frac{e^{\beta_{2} \omega_{i t}}}{\beta_{2}}\left(\beta+\beta_{1} \log \omega_{i t}+\beta_{2} m_{i}+\boldsymbol{\beta}_{2}^{-\prime} \boldsymbol{z}_{i t}^{-}\right)-\frac{\beta_{1}}{\beta_{2}} E i\left(\beta_{2} \omega_{i t}\right) \\
& +\frac{e^{\beta_{2} \omega_{i t}}}{\beta_{2}}\left(\beta_{3} \frac{1}{n_{i}} \sum_{j \in N_{i}} e_{j t}+\beta_{4} \frac{1}{n_{i}} \sum_{j \in N_{i}} \log \omega_{j t}+\boldsymbol{\beta}_{\mathbf{5}}^{\prime} \frac{1}{n_{i}} \sum_{j \in N_{i}} \boldsymbol{z}_{j t}\right) .
\end{aligned}
$$

The first two expressions on the right-hand side give the individual indirect sub-utility function and the third one represents the social indirect sub-utility function.
} 
to the linear-in-means semi-log effort function. In this model, strategic complementarity in work effort (due for instance to social conformity) is equivalent to having $\beta_{3}>0$. The reflection problem does not arise in the Recursive treatment since mean peer effort is strictly exogenous. This follows from the fact that $E\left[\varepsilon_{i t} \mid \boldsymbol{e}_{-}, \boldsymbol{X}\right]=0$, where $\boldsymbol{e}_{-}$is the vector of effort of all individuals from the Baseline treatment in all periods and $\boldsymbol{X}$ is the matrix of all other explanatory variables in all periods from both the Baseline and the Recursive treatments. Social interaction effects are unlikely to arise through the error terms since the information about the Baseline treatment is controlled for in the determinist part of the model.

In our model, mean peer performances and contextual effects are captured by $\beta_{3}$, and $\left(\beta_{4}, \boldsymbol{\beta}_{\mathbf{5}}{ }^{\prime}\right)$, respectively. Under the assumption that $\alpha=\beta, \alpha_{1}=\beta_{1}, \boldsymbol{\alpha}_{\mathbf{2}}=\boldsymbol{\beta}_{\mathbf{2}}$, the pooled set of Baseline and Recursive individuals are said to form a directed bipartite network. It is as if the population contained two distinct subsets with those in the Baseline subset corresponding to peers to those in the Recursive subset, but with no connection within each subset. If the above assumption holds, equations (1) and (2) can be combined into single pooled model:

$$
\boldsymbol{e}_{t}=\beta \boldsymbol{\imath}_{t}+\beta_{1} \boldsymbol{w}_{t}+\beta_{2}^{\prime} \boldsymbol{Z}_{t}+\beta_{3} \boldsymbol{R} \boldsymbol{e}_{t}+\beta_{4} \boldsymbol{R} \boldsymbol{w}_{t}+\boldsymbol{\beta}_{5}^{\prime} \boldsymbol{R} \boldsymbol{Z}_{t}+\varepsilon_{t} \text { with } E\left[\varepsilon_{t} \mid \mathbb{R} \boldsymbol{e}, \boldsymbol{X}\right]=0
$$

where $\boldsymbol{e}_{t}$ is the concatenated vector of effort levels at period $t, \boldsymbol{\imath}_{t}$ is an appropriately dimensioned unit-vector, $\boldsymbol{w}_{t}$ is the vector of wages, $\boldsymbol{Z}_{t}$ is the matrix of the individual characteristics, $\boldsymbol{R}$ is the social interaction matrix, where $\boldsymbol{R}_{i j}=1 / n_{i}$ if $j$ is a member of the Baseline treatment and is a peer of individual $i$ in the Recursive treatment, and $\boldsymbol{R}_{i j}=0$ otherwise, $\mathbb{R}=\operatorname{diag}(\boldsymbol{R})$ is a block-diagonal matrix with $\boldsymbol{R}$ on its diagonal. The vector $\boldsymbol{R} \boldsymbol{e}_{t}$ corresponds to the mean effort of each reference group at $t$ and is equal to 0 for Baseline individuals. The vector of all reference groups' mean effort in all periods is given by $\mathbb{R} \boldsymbol{e}$, where $\boldsymbol{e}$ is the concatenation of $\boldsymbol{e}_{t} \forall t$, and is strictly exogenous in equation (3). This model 
is identified ${ }^{11}$ and can be estimated using pooled OLS or a random effects (RE) panel model. Session fixed effects can easily be introduced in this specification.

\subsection{Simultaneous treatment}

In the Simultaneous treatment, two-way interactions between $n$ individuals are structured through an exogenous network designed by the experimenter. As before, individual $i$ is assigned to a specific reference group $N_{i}$ which is composed of $n_{i}$ peers. He behaves non-cooperatively and ignores the impact his own output level may have on other members of the network. We assume that each individual maximizes a utility function subject to budget and time constraints and conditional upon his expectations about his reference group's mean work effort and characteristics. We assume that the model has reached a noncooperative Nash social equilibrium with self-consistent expectations. In other words, the expected and the equilibrium effort levels are equal. This is true for all network members.

At the Nash equilibrium, the effort level of individual $i$ at period $t, e_{i t}$, is a function of his own wage and characteristics, as well as the average effort level, wage and other characteristics of his reference group at the same period:

$$
e_{i t}=\gamma+\gamma_{1} w_{i t}+{\gamma_{\mathbf{2}}}^{\prime} \boldsymbol{z}_{i t}+\gamma_{3} \frac{1}{n_{i t}} \sum_{j \in N_{i}} e_{j t}+\gamma_{4} \frac{1}{n_{i}} \sum_{j \in N_{i}} w_{j t}+\gamma_{\mathbf{5}} \frac{1}{n_{i}} \sum_{j \in N_{i}} \boldsymbol{z}_{j t}+\varepsilon_{i t}
$$

with $E\left[\varepsilon_{i t} \mid X\right]=0$ and where $\left|\gamma_{3}\right|<1$. In matrix notation, our structural model is given by:

$$
\boldsymbol{e}_{t}=\gamma \boldsymbol{\imath}_{t}+\gamma_{1} \boldsymbol{w}_{\boldsymbol{t}}+\gamma_{2}^{\prime} \boldsymbol{Z}_{t}+\gamma_{3} \boldsymbol{G} \boldsymbol{e}_{t}+\gamma_{4} \boldsymbol{G} \boldsymbol{w}_{t}+\gamma_{\mathbf{5}}^{\prime} \boldsymbol{G} \boldsymbol{Z}_{t}+\boldsymbol{\varepsilon}_{t}
$$

with $E\left[\varepsilon_{t} \mid \boldsymbol{X}\right]=0$, where $\boldsymbol{G}$ is a row-normalized social interaction matrix, with $\boldsymbol{G}_{i j}=1 / n_{i}$ if $j$ is a peer of $i$, and 0 otherwise. It is worth emphasizing that equations (3) and (5) differ in two important aspects. First, while in the Simultaneous model (equation (5)) social

\footnotetext{
${ }^{11}$ This property is also consistent with a theorem in BDF which states that the model is identified whenever $\boldsymbol{R}^{2}=0$ (which is the case here), $\beta \neq 0$ and at least one individual is isolated in the social network (see Appendix A in BDF paper).
} 
interactions occur in real time within the same session, in the Pooled model (equation (3)), participants in a given session are matched to participants who have played in isolation in a previous session. Therefore the models do not reflect the same informational environment. This explains why we allow the parameters of these two equations to be different. Second, the variable $\boldsymbol{R} \boldsymbol{e}_{t}$ is exogenous in equation (3) whereas $\boldsymbol{G} \boldsymbol{e}_{t}$ is endogenous in equation (5). It is therefore crucial to establish the conditions under which the Simultaneous treatment model is identified. To do so, we start by deriving its reduced form. By assuming that $\left|\gamma_{3}\right|<1$, it follows that $\boldsymbol{I}-\gamma_{3} \boldsymbol{G}$ is invertible. The reduced form of model (5) is thus given by:

$$
\begin{aligned}
\boldsymbol{e}_{t} & =\gamma\left(\boldsymbol{I}-\gamma_{3} \boldsymbol{G}\right)^{-1} \boldsymbol{\imath}_{t}+\left(\boldsymbol{I}-\gamma_{3} \boldsymbol{G}\right)^{-1}\left(\gamma_{1} \boldsymbol{I}+\gamma_{4} \boldsymbol{G}\right) \boldsymbol{w}_{t} \\
& +\left(\boldsymbol{I}-\gamma_{3} \boldsymbol{G}\right)^{-1}\left(\gamma_{2} \boldsymbol{I}+\gamma_{5}^{\prime} \boldsymbol{G}\right) \boldsymbol{Z}_{t}+\left(\boldsymbol{I}-\gamma_{3} \boldsymbol{G}\right)^{-1} \boldsymbol{\varepsilon}_{t}
\end{aligned}
$$

Since the inverse matrix is unique, the model is coherent and the Nash equilibrium is unique. The macro reduced form, which includes all periods, is given by:

$$
\begin{aligned}
\boldsymbol{e} & =\gamma\left(\mathbb{I}-\gamma_{3} \mathbb{G}\right)^{-1} \boldsymbol{\imath}+\left(\mathbb{I}-\gamma_{3} \mathbb{G}\right)^{-1}\left(\gamma_{1} \mathbb{I}+\gamma_{4} \mathbb{G}\right) \boldsymbol{w} \\
& +\left(\mathbb{I}-\gamma_{3} \mathbb{G}\right)^{-1}\left(\gamma_{2} \mathbb{I}+\gamma_{5}^{\prime} \mathbb{G}\right) \boldsymbol{Z}+\left(\mathbb{I}-\gamma_{3} \mathbb{G}\right)^{-1} \boldsymbol{\varepsilon}
\end{aligned}
$$

where $\mathbb{G}=\operatorname{diag}(\boldsymbol{G})$ is the block-diagonal social interaction matrix for the $T$ periods. The intercept is $\gamma$ if the individual is isolated and $\gamma /\left(1-\gamma_{3}\right)$ if not. Equation (7) enables us to evaluate the impact of a marginal shock in $\gamma$ (i.e., a common exogenous change within the network) on an individual's output when the endogenous peer effect is taken into account. When there are no isolated participants this is equivalent to $\partial\left(E\left(\boldsymbol{e}_{i t} \mid \cdot\right) / \partial \gamma=1 /\left(1-\gamma_{3}\right)\right.$ and corresponds to a "social multiplier" in our model. ${ }^{12}$ When $\gamma_{3}>0$ (strategic complementarity

\footnotetext{
${ }^{12}$ When there are isolated participants, the social multiplier is a convex combination of the social multiplier when no individuals are isolated and when all individuals are isolated, that is, $(1-\delta)\left[1 /\left(1-\gamma_{3}\right)\right]+\delta$, where $\delta$ is the fraction of participants who are isolated.
} 
in work effort), the social multiplier is larger than 1 and the initial shock is amplified by the social interactions.

As for identification, BDF have shown that if $\boldsymbol{I}, \boldsymbol{G}$, and $\boldsymbol{G}^{2}$ are linearly independent then peer effects are identified. ${ }^{13}$ This condition is satisfied whenever there are intransitive triads in the network, that is, whenever at least two individuals are separated by a link of distance 2. For example, if workers $A$ and $C$ are not peers but are linked through peer $B$, then peer effects are identified. ${ }^{14}$ When session fixed effects are possibly correlated with the explanatory variables, the BDF condition becomes more restrictive. In the latter case the model is identified if $\boldsymbol{I}, \boldsymbol{G}, \boldsymbol{G}^{2}$, and $\boldsymbol{G}^{3}$ are linearly independent. This condition holds whenever two individuals are separated by a link of distance 3. A simple estimation strategy is to use session fixed effects along with an IV estimator whose instruments are $\mathbb{G}^{2} \boldsymbol{X}, \mathbb{G}^{3} \boldsymbol{X}, \ldots($ see BDF $)$.

\section{Experimental design and procedures}

Following the above theoretical discussion, our challenge is to devise experiments that can adequately measure peer performance and contextual effects in an efficient manner. In what follows, we describe the three treatments that were administered to participants and stress how they relate to the theoretical model. For that purpose, we use a between-subject design.

\subsection{The Baseline treatment}

As mentioned in Section 2.1, Baseline participants play in isolation. Their performance is inherently interesting but the main purpose of this treatment is provide matches or peers to players in the Recursive treatment. Two sessions were organized, each one comprising 16 periods. Each session involved 18 participants aligned along 3 rows. In each period,

\footnotetext{
${ }^{13}$ Conceptually, $\boldsymbol{G}^{2}$ corresponds to the interaction matrix of individuals' peers with their own peers.

${ }^{14}$ More generally, peer effects are identified when individuals do not interact in groups.
} 
participants are invited to perform a task during two and a half minutes. The task consists

in multiplying two-digit numbers by one-digit numbers (e.g. $15 \times 3$ or $22 \times 7$ ). To insure homogeneity of treatment across participants and sessions, the same tasks are asked from everyone in the same order. Once the two numbers have been displayed on the computer screen, participants enter the answer at will. If correct, a new task is displayed on the screen. Otherwise an error message is displayed and the answer must be entered anew. The screen keeps track of the number of correct answers and the remaining time until the period ends. Calculators, pen or electronic devices are prohibited. Before they begin, participants are informed that they are free to read the magazines that lay on their desk. These serve as a mimicking device to on-the-job leisure.

Compensation is based on a piece-rate system. At the beginning of each period, a piecerate of either $€ 0.10$, $€ 0.50$, or $€ 1$ is randomly assigned to each participant and displayed onto the screen. Earnings in each period is simply the number of correct answers times the piece-rate. Incorrect answers do not count against earnings. The number of correct answers and the potential earnings are displayed at the end of each period. When the session ends, actual compensation corresponds to the earnings of a randomly selected period drawn independently for each participant. In addition, participants are paid a fixed randomly selected show-up fee of either $€ 2, € 4$, or $€ 6$ at the beginning of the session. In a standard labor supply model this would correspond to unearned income.

\subsection{The Recursive treatment}

The setup of the Recursive treatment is similar to that of the Baseline treatment save for unidirectional interactions. Indeed, participants are informed that they are matched to either one or two peers. In addition they are told their peers played in a previous session and that the match will remain the same for the duration of the session. Those seated at the end of a row are matched to a single peer (their corresponding neighbor of a previous session), while all others are matched to two peers (their corresponding left and right neighbors of a previous session). This spatial configuration parallels that of the Simultaneous treatment 
although in both the Recursive and the Simultaneous treatments participants are not aware of this. Figure 1 depicts the graph of the directed bipartite network. The nodes correspond to the players and the arrows point towards their peers.

At the beginning of the session, information on peer characteristics are displayed on the screen. These include average age, school, number of school years, gender, relative family wealth, and show-up fee. At the beginning of each period, in addition to own piece-rate, information about average peer piece-rate and performance are displayed on the screen. Participants are also informed that their peers had to perform the exact same multiplications as themselves, and in the same order. This ensures that the level of difficulty of the task is kept constant across participants. At the end of each period, a summary screen displays own performance, piece-rate and potential earnings as well as average peer piece-rate and performance.

Figure 1: Graph of a Directed Bipartite Network

Baseline Treatment

Recursive treatment

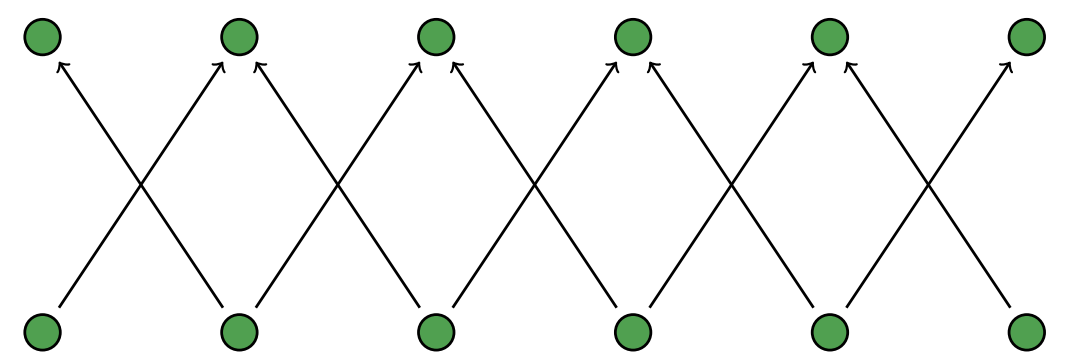

\subsection{The Simultaneous treatment}

The setup of the Simultaneous treatment is similar to that of the Recursive treatment except that the interactions occur concurrently. The discussion of Section 2.3 has underscored the intimate link between the structure of a network, as described by its graph matrix $\boldsymbol{G}$, and the identifiability of the endogenous peer effect. In designing a specific network, we have tried to satisfy two separate criteria. First, identification requires that the network 
structure be such that the matrices $\boldsymbol{I}, \boldsymbol{G}, \boldsymbol{G}^{2}, \boldsymbol{G}^{3}$ be linearly independent. The lower the collinearity between the latter matrices, the more precise the resulting estimate of the peer effect will be. Second, external validity requires the network to reflect real life interactions between individuals within their work environment.

Based on these two criteria, we have chosen an undirected line social network. Thus each row of six participants in the laboratory constitutes a network whose graph is depicted in Figure 2. Such a network ensures that at least two participants are separated by a link of distance 3, a sufficient condition for identification of the peer effect to hold. The degree of collinearity within this type of network can be ascertained by computing the condition number of the matrix resulting from the vectorization and concatenation of the above four matrices (see BDF). ${ }^{15}$ Our undirected line network has a condition number of 7.7 which is quite low and should thus yield relatively precise estimates of the peer effect. An undirected line network is also likely to have good external validity properties. Indeed, it mimics many work environments in which employees work in isolation but have the ability to observe their colleagues' pace and performance (as in open space offices or workshops).

Figure 2: Graph of the Undirected Line Network

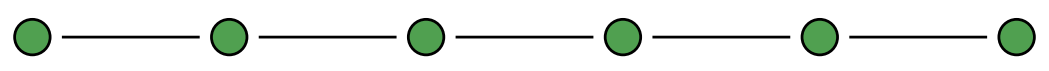

As shown in Figure 2, participants located at the end of a row are matched to a single peer while all others are matched to two peers. Participants are not aware of the network structure. They are not told that their peers are their direct neighbors but we verified they understood their peers were present in the room.

Contrary to the Baseline and Recursive treatments, a session consists of only four pe-

\footnotetext{
${ }^{15}$ The condition number of a matrix $\boldsymbol{A}^{\prime} \boldsymbol{A}$ is given by the square root of the ratio of its maximum and minimum eigenvalues. A condition number above 30 is indicative of serious collinearity.
} 
riods. Each period comprises up to five rounds of two and a half minutes each to allow convergence to the Nash equilibrium. The duration of the Simultaneous sessions is thus similar to the other two. Comparisons between treatments should therefore not be contaminated by fatigue.

The Simultaneous session unfolds pretty much like the Recursive session. Information on peer characteristics are displayed on the screen at the beginning of the session. As each period begins, information is provided on own piece-rate as well as average peer piece-rate. At the end of each round, average peer performance is displayed on the screen. Next, participants are told whether the period has ended or whether a new round is about to begin. They are not aware of the convergence rule; they only know that each period may consist of several rounds and that they keep the same piece-rate throughout a period. The period ends once the difference in average output between two successive rounds within a given network is less than $5 \%$. When this criterion is satisfied, the model is said to have reached a non-cooperative Nash social equilibrium with self-consistent expectations. In other words, expected and contemporaneous peer mean performance are almost equal for each network member. ${ }^{16}$

\subsection{Experimental procedures}

The experiment was programmed using the Z-Tree software (Fischbacher (2007)). All sessions were conducted at GATE (Groupe d'Analyse et de Théorie Économique) in Lyon, France. Undergraduate students from the local engineering and business schools were invited via the ORSEE software (Greiner, 2004). Between 6 and 18 participants took part in each session, for a total of 189 participants. As outlined in Table A1 of Appendix A, two sessions of the Baseline treatment were held with 18 participants each, three sessions of the Recursive treatment involved 39 participants and finally, 7 sessions of the Simulta-

\footnotetext{
${ }^{16}$ They are only "almost" equal for two reasons: First, the convergence criterion is not zero. Second, for reasons of tractability, the criterion is applied at the network level, not at the individual level. This may generate measurement errors that are taken into account by using an IV approach.
} 
neous treatment involved 114 participants. ${ }^{17}$ Participants in the Simultaneous treatment are more numerous since each session consists of only four periods.

Upon arrival in the laboratory, participants drew a ticket from a bag assigning them to a specific computer terminal. The instructions describing the task, the payment scheme and the available set of information throughout the experiment were distributed and read aloud (see Appendix 2). Once reading was completed, participants were distributed a questionnaire to assess their understanding of the rules. Answers were verified individually. They next had to report their age, gender, school, number of years of study, and belief about the wealth of their family relative to that of the other students of the same school on a scale from 1 to 10. This was followed by a practice period of two and a half minutes after which the experiment per se began.

At the end of the final period, participants were told which period (and which round in the Simultaneous treatment) was randomly selected for payment along with their payoff. They next had to complete an exit survey. On average, a session lasted 60 minutes and participants earned $€ 14.36$ with a standard deviation of $€ 8.76$, including an average $€ 4$ show up fee (minimum $=€ 2$, maximum $=€ 40)$.

\section{Results}

We start by presenting descriptive statistics on the sample of participants and the main parameters of the treatments. We then turn to econometric results.

\subsection{Summary statistics and prima facie evidence}

The first panel of Table 1 reports the means and standard deviations of the main variables used in the econometric analysis. The statistics are presented separately for the three treatments. The three rightmost columns of the table report the p-values of two-tailed test

\footnotetext{
${ }^{17}$ Because we accepted three surplus participants in the Recursive treatment, the performances of three workers in the baseline treatment have been used twice.
} 
statistics of equality between the recursive/baseline treatments, the simultaneous/baseline treatments and the recursive/simultaneous treatments, respectively. According to the pvalues, nearly all variables are balanced across the three treatments, save for age, relative family wealth, and age of peers. Indeed, participants in the recursive and simultaneous treatment are slightly older than those of the baseline treatment, whereas participants in the recursive treatment report the lowest relative family wealth. Finally, participants in the simultaneous treatment are paired with slightly older peers than those in the recursive treatment. This is because the latter are paired with individuals from the baseline treatment who happen to be younger. Participants from the Central Engineering School are singled out because the are likely to perform better in mental calculations than other participants. They represent between $23 \%$ and $31 \%$ of participants in the different treatments. Likewise, participants in the recursive treatment are slightly less likely to be matched with peers from the Central Engineering School (CES, hereafter) than those of the simultaneous treatment, although the difference is not statistically significant.

The bottom panel of the table focuses on the parameters and the outcomes of the different treatments. The average piece-rate, not surprisingly, is identical across treatments. The mean performance of each treatment is illustrated in Figure 3(a). The height of the boxes represent the mean values while the standard errors are represented by whiskers. At face value, as we move from a non-competitive situation (baseline) to gradually more competitive environments, mean performances increase slightly. Decomposing mean performances by gender in Figure 3(b) unearths interesting features. First, both male and female participants increase their performances slightly as we move from the baseline to the recursive treatment. In the more competitive simultaneous environment, men increase their performance by a sizeable 3 to 4 units compared to the other treatments. Women, on the other hand, do not increase their performance. If anything, it decreases slightly.

The reasons performances vary across treatments (and gender) are manyfold. Peer pressure and characteristics are certainly important determinants. Simple mean comparisons 
are interesting but uninformative because they omit the influence of contextual factors and of endogenous responses, at least when focusing on the simultaneous treatment. Proper comparison thus requires all factors be taken into account and the endogeneity of peer effects adequately be dealt with.

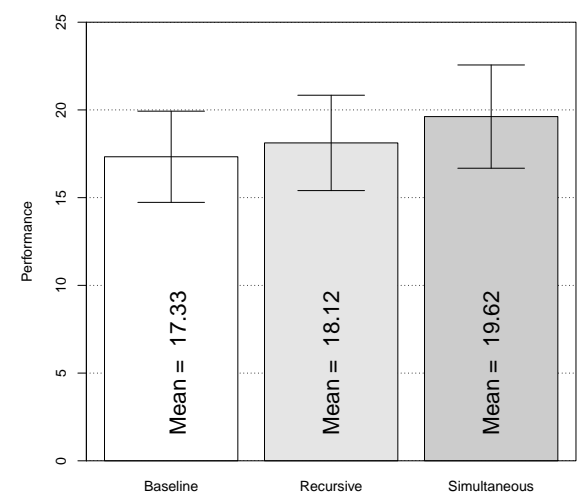

(a) Treatment

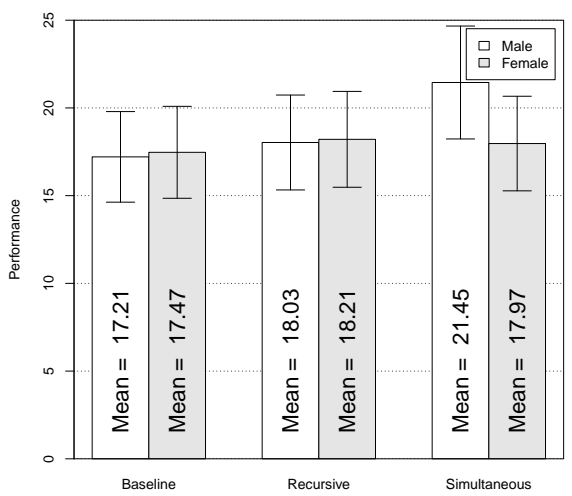

(b) Treatment and Gender

Figure 3: Mean Performances and Standard Deviations, by Treatment and Gender

\subsection{Estimation Strategy}

Our experiments involve three different treatments: (1) Baseline; (2) Recursive; (3) Simultaneous. We estimate all three separately and in addition we estimate treatments (1) and (2) jointly. The latter specification is equivalent to a directed bipartite network. Its validity rests upon implicit pooling restrictions that can be tested.

Two sets of regressions are used in each case in order to investigate the robustness of our results. In the simultaneous model, we use both instrumental variable (IV) and a random effects IV estimators. ${ }^{18}$ The selection of instruments is made difficult by the small number of networks at our disposal. BDF suggest using a generalized IV approach based on the

\footnotetext{
${ }^{18}$ We also estimated the model using fixed effects IV. However, the parameter estimate of the peer effect was very close to the one obtained using a random effects model. Moreover, the former approach does not allow to identify the impact of individual and contextual effects that are time invariant.
} 


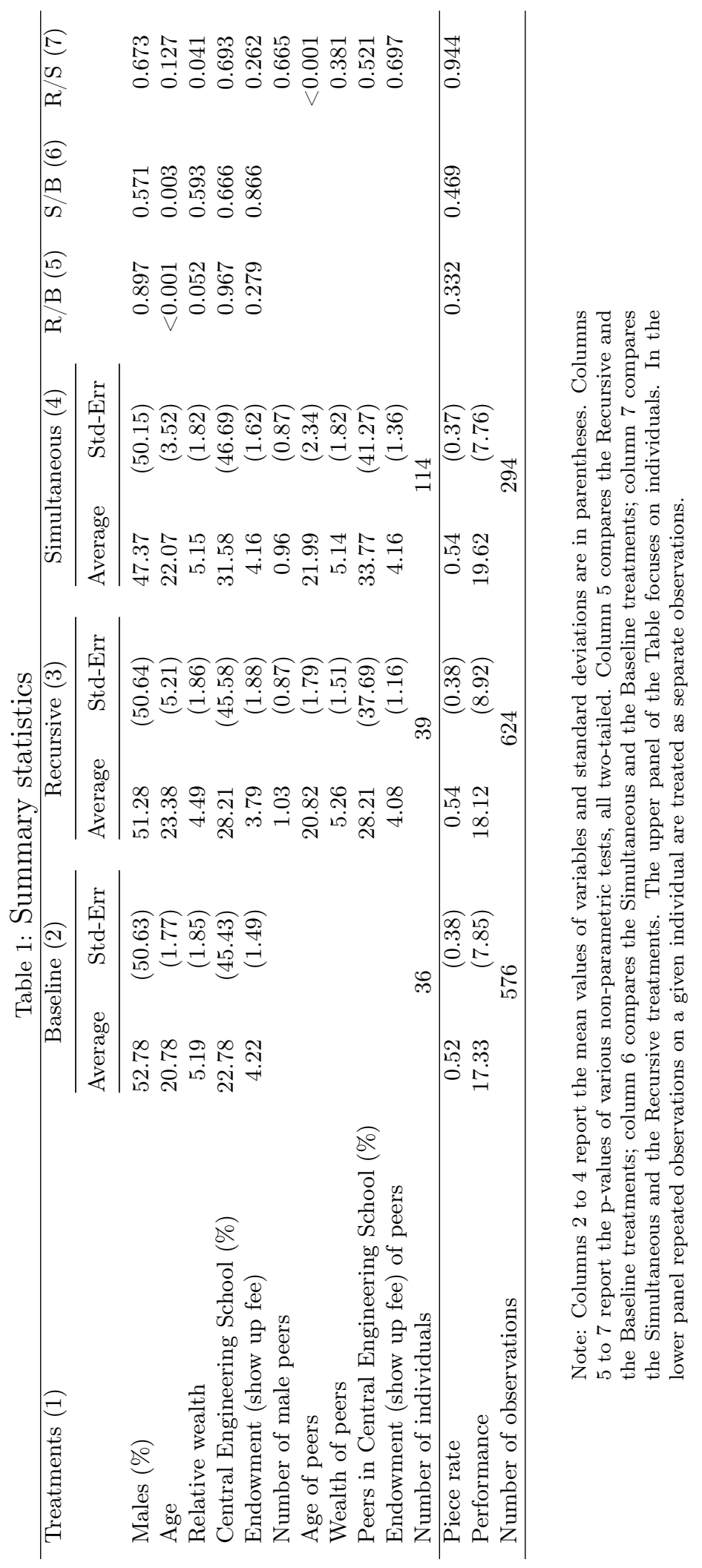


reduced form of the macro model. Unfortunately, this is likely to yield biased estimates in small samples. In our particular setup, limiting the instruments to $\mathbb{G}^{2} \boldsymbol{X}$ at the network level turns out to be appropriate. ${ }^{19}$ Only observations in rounds that met our convergence criterion for the Nash equilibrium are used to estimate the model. Yet because the criterion is arbitrary and defined at the network rather than at the individual level, contemporary peers' labor supply may differ from its expected value, as requested for the Nash equilibrium to hold. Fortunately, the IV approach is a suitable remedy for such measurement errors.

In the other three specifications peer effects are not endogenous. Simple panel OLS and RE can thus be used to estimate the parameters of the models. Valid statistical inference requires robust standard errors clustered at the individual level. Panel OLS provide consistent estimators but are not as asymptotically efficient as RE estimators.

All specifications include a time trend to account for learning effects, ${ }^{20}$ session fixed effects and the following individual effects: period-specific piece-rate (in log), relative family wealth, age, gender, initial endowment and a dummy indicator for attending the Central Engineering School. Subjects from this school represent $22.8 \%$ of the sample and are known to be selected for their mathematical abilities. Recursive and simultaneous treatments include mean peer performance as well as mean peer values (i.e., so-called contextual variables) in addition to the aforementioned variables.

\subsection{Estimation Results}

The estimation results are presented in Tables 2-4. In Table 2 the regressions include all the participants in the various treatments. Tables 3 and 4 are identical to Table 2 except that they report results for men and women separately.

\footnotetext{
${ }^{19}$ Including $\mathbb{G}^{3} \boldsymbol{X}$ and $\mathbb{G}^{4} \boldsymbol{X}$ did not qualitatively change the results.

${ }^{20}$ Using a quadratic expression in time to account for potential fatigue does not qualitatively affect the results.
} 


\subsubsection{Estimation Results for the Entire Sample}

We begin with the entire sample in Table 2. Few parameter estimates are statistically significant in the Baseline treatment. Both the OLS and RE models obtain that individual performance increases with the number of periods. The learning effect is relatively important $(=0.264)$. Contrary to the OLS model, the RE model finds a positive and significant relation between piece-rate and performance $(p<0.01)$. The parameter estimate suggests that increasing the piece-rate twofold increases output by as much as 0.765 units per period.

In the recursive treatment (column (2)), learning effects are still present, but are nearly halved in comparison to those of the baseline treatment. Individuals effects also yield interesting results. The piece-rate still has a positive and statistically significant effect on performance, but is much larger than previously. The parameter associated with age suggests that older individuals perform better, perhaps because they are more accustomed to do mental calculations. As expected, students from the Central Engineering School perform much better. According to the RE model they have a production level in excess of 10 units relative to other subjects $(p<0.01)$. The Endowment (the show-up fee) parameter estimate is negative. This can be interpreted as an income effect on work effort if leisure is a normal good (see Dickinson, 1999). Finally, male performance is lower by as much as four units $(p<0.05)$. This result is consistent with recent findings (see Else-Quest et al., 2010) according to which girls outperform boys in mathematics assessments tests in countries with a high degree gender equity (e.g., France), and especially so when the tasks involve simple subtractions and complex multiplications (see Wei et al., 2012). As for contextual effects, only peer mean age is statistically significant $(p<0.1)$. Its negative sign suggests that when peers are younger, subjects may be inclined to increase their performance so as to remain competitive.

Interestingly, peer performance enhances individual performances by as much as 0.26 each period. The estimate is statistically significant both in the OLS and RE models, but much more so in the latter case. This result is consistent with an emulation effect. 
The Pooled model (Column (3)) combines the Baseline and the Recursive samples under the null hypothesis that the parameters are the same. The latter is rejected at the $5 \%$ level but not at the $1 \%$ level $(p=0.042)$. Using a $1 \%$ decision rule, the pooled model can be analyzed as a linear-in-means model with a directed bipartite network.

In general the OLS and RE parameter estimates of the individual effects are smaller than those of the Recursive treatment but larger than those of the Baseline treatment. This is not surprising because the pooled sample must necessarily yield estimates that correspond to some average of the two. Moreover, the Endowment and the Gender effects are no longer statistically significant, as was the case with the Baseline model. As with the Recursive model, mean peer age is the only statistically significant contextual effect. However, the OLS and RE coefficients in the Pooled model are now much smaller in absolute value.

Results from Table 2 indicate that the OLS and the RE mean peer performance coefficients are quite similar $(=0.292$ and 0.230$)$, statistically significant at the $1 \%$ level, and very close to the corresponding parameter estimate of the Recursive treatment. The implicit social multiplier is equal to $1.15(=1 / 2+1 / 2[1 /(1-0.230])$, based on RE model.

The last column of the table focuses on the Simultaneous treatment. Sargan's test indicates that the instruments are valid and that the over-identification restrictions are not rejected ( $\mathrm{p}$-value $=0.46)$. As in all previous treatments, the period variable is positive and statistically significant. The parameter estimate is much larger than previously, presumably because each period includes many rounds and thus aggregates individual round effects. ${ }^{21}$

The piece-rate effect is statistically significant and large $(=0.957)$ when the model is estimated using an IV-RE approach. Interestingly, women respond to financial incentives as much as men do, contrary to the previous treatments. This is consistent with the findings of Paarsch and Shearer (2007), albeit in an entirely different context. As before, performance increases with age and is higher for students attending the Central Engineering school. The

\footnotetext{
${ }^{21}$ We used periods as opposed to rounds to proxy the learning effect since the latter is not exogenous as it depends on how fast the Nash equilibrium is reached.
} 
only contextual variable that affects individual performance is mean peer endowment. The higher the latter, the more individuals may be motivated to increase their production so as to compensate for their peers' more favorable show-up fee draw.

Contrary to the Recursive and Pooled models, mean peer performance has no statistically significant impact on performance. This is rather puzzling. Recall from Figure 3(a) that mean performance generally increased as we moved from the Baseline treatment to the Recursive treatment, and from the latter to the Simultaneous treatment. Part of the explanation perhaps lies in differential gender responses to a more competitive environment. Indeed, Figure 3(b) showed that women slightly decreased their performance when working in a simultaneous environment. Men, on the other hand, increased their output dramatically. The fact that women are less likely to adjust their effort to the performance of their peers, compared to men, could also be somewhat related to gender differences in processing information on relative ability. For example, Möbius et al. (2011) have observed that women are more "ego-defensive" in the sense that they are less confident than men, are also significantly more conservative updaters and appear to be more averse to feedback on relative performance. Differential gender response will be investigated below.

All in all, the parameter estimates are relatively robust across specifications. In all treatments individuals exhibit some form of learning, they respond to financial incentives, and more or less the same variables are statistically significant. In addition, the Recursive and Pooled models both find that mean peer performance affects individual performances. The only surprising result concerns peer performance in the simultaneous model. With an aim at better understanding this result, we now turn to results that treat men and women separately.

\subsubsection{Estimation Results by Gender}

According to Table 2 the mean peer effect on individual performances differs considerably between the recursive and the simultaneous treatments. Since both treatments are set up within the same parametric framework, the discrepancy between the two may have more 
to do with differentiated gender responses to the two environments. Indeed, the literature provides ample evidence that men and women react differently in competitive environments. Research in psychology has found that men exhibit greater sensitivity to rewards (Torrubia et al., 2001; Ray Li et al., 2007) and value earnings more than women do perhaps for evolutionary reasons (Browne, 2002; Kanasawa, 2005). The economics literature has found that contrary to men, whose performance is enhanced by competitive incentives, women tend to shy away from competition (Gneezy et al., 2003; Niederle and Vesterlund, 2007).

Tables 3 and 4 report the estimation results for males and females, respectively. In both cases, Sargan's tests indicate that the instruments are valid and that the over-identification restrictions are not rejected ( $\mathrm{p}$-value $=0.41$ and 0.40 , respectively). A close inspection reveals important behavioral differences. To start with, men exhibit very little learning in most specifications. The positive learning effect in the baseline treatment carries through to the pooled specification but shrinks considerably because there is no learning in the recursive treatment. Women, on the other hand, exhibit consistent and significant learning in each specification.

Individual effects also vary considerably across gender. As found in the psychology literature, men appear to be much more sensitive to financial incentives. In nearly all specifications, their productivity is intimately linked to the piece-rate. As expected, women are much less responsive. Their parameter estimate in the OLS-RE model of the baseline model is statistically significant but it is much smaller than that of men. Interestingly, the parameter estimate in the simultaneous treatment is significant and of the same order of magnitude as that of men. ${ }^{22}$ Age effects are very similar across gender. Endowment effects are never statistically significant, save for the baseline specification which shows women produce more when their endowment (show-up fee) increases. This counterintuitive result may in fact be interpreted as a gift exchange effect (see Akerlof, 1982): In the absence

\footnotetext{
${ }^{22}$ We performed joint tests of equality for each specification. The null hypothesis is always rejected except in the Baseline OLS model.
} 
of competitive influences, women in the baseline treatment may feel compelled to increase their productivity when they are awarded a greater show-up fee. Finally, attending the Central Engineering School is generally associated with a larger productivity for both men and women. Yet, the parameter estimates vary across the different specifications in a manner that is consistent with men being more competitive than women. Hence, contrary to women, men attending the CES are no more productive than other participants in the baseline treatment. In the recursive treatment, both men and women attendees are equally more productive. In the more competitive simultaneous treatment, male attendees outperform other participants by a large margin whereas female attendees are no different. There are no clear reasons why technically skilled male and female students should exacerbate or downplay their comparative advantage across the different treatments. The parameter estimates nevertheless suggest men increase their effort when playing in a competitive environment, whether recursive or simultaneous. Women, on the other hand, consistently outperform other participants so long as they are not playing against peers in real time.

Peer contextual effects more or less mirror individual effects: They vary across gender and specification and are broadly consistent with men being more competitive. Whereas women appear to be indifferent to their peer's mean wage, men tend to respond negatively. The increase in mean peer wage rate, holding mean peer performance constant, may be interpreted as though peers are leisure lovers (i.e., their income effect is equal to their substitution effect). Social conformity may thus induce men to perform less. The mean peer age also affects male and female participants differently. It has both a negative (recursive) and positive (simultaneous) impact on women's productivity, but no such effect on men's productivity. Mean peer endowment affects both men and women positively, but only in the pooled model for women, and only in the more competitive simultaneous model for men. Finally, the proportion of peers attending the CES has little effect on women's productivity but a large and negative impact on men's productivity in the simultaneous treatment. ${ }^{23}$

\footnotetext{
${ }^{23}$ By construction, the proportion of peers attending the CES is one of $0 \%, 50 \%$ or $100 \%$.
} 
Thus men who are told they are matched with CES students may be somewhat discouraged and chose to spend little effort competing against more able individuals.

Unsurprisingly, mean peer performance effects vary across gender but nevertheless exhibit relative consistency gender wise. Hence, according to Table 3 males are relatively sensitive to mean peer performance in every specification. The responsiveness increases as we move from the recursive to the more competitive simultaneous treatment. This is valid for the OLS, RE and IV estimators. As for women, the RE estimators in Table 4 indicate that mean peer performance increases individual performances in the recursive and pooled specifications by the same amount. The corresponding parameter estimates in the simultaneous treatments is negative but lacks statistical significance. This is in line with the aforementioned literature according to which women do not thrive on competition.

The empirical analysis based on the entire sample has shown that individuals behave more or less as predicted by theory: they (more or less) respond to financial incentives and are (more or less) sensitive to peer characteristics and performances. The need to analyze men and women separately was prompted by the fact that peer performance effects surprisingly vanished in the more competitive simultaneous environment. Many have suggested that men and women's behavior differ significantly in such environments. The results of Tables 3 and 4 support this contention. Our results show that not only do the endogenous peer effects differ across gender, so do the contextual peer effects and individual effects.

\section{Conclusion}

Social interactions within networks are seldom taken into account in studies of work effort. This is rather surprising given that few workers ever work in isolation. The omission is partly due to the fact that workplace surveys hardly ever document reference group within firms. In addition, estimating a work effort model with peer effects raises notoriously difficult identification problems. This is because social networks are likely endogenous, and disentangling peer performance effects from peer contextual effects can only be achieved 
under very strong assumptions. In this paper, we argue that a carefully designed laboratory experiment can help solve these problems for two reasons. First, individual reference groups can be determined exogenously by the experimentalist. Second, the network can be designed in accordance with recent developments by Bramoullé et al. (2009) who characterize the network structures that guarantee identification of all social interactions within the standard linear-in-means model.

Our real-effort experiment is based upon two types of social networks. The first is a bipartite directed network. Participants in the Recursive treatment are matched to Baseline participants who played previously in isolation. By construction, such a network is void of any identification or simultaneity problem. The second is a so-called undirected line network. In this Simultaneous treatment, players interact with their peers in real time. The network is designed as per Bramoullé et al. (2009) so as to insure identification of the endogenous and contextual peer effects. Instruments are intrinsically determined by the structure of the network.

Determining whether and why individual performances are related to peer performances is important from a policy perspective. This is why the Recursive and Simultaneous networks are designed so as to mimick real-life work situations. The former is akin to a situation whereby workers on an assembly line learn about the output level of their peers in a previous work shift. The latter corresponds to the situation of a cashier in a large retail store or workers on an assembly line who can both observe the performances of their co-workers or be observed by them.

Our empirical analysis has unearthed a number of important results about worker behavior in a network setting. On the whole, workers behave as predicted by theory. They respond to financial incentives and are sensitive to peer characteristics and performances. This means in particular that being surrounded by or informed about less productive workers will tend to reduce their performance, while observing more productive workers will encourage them to perform better. Studies which strictly focus on financial incentives such 
as wages or piece rates thus probably overestimate their impact on productivity. Yet our most noteworthy results concern differences in gender responses to social interactions. Men undoubtedly are more sensitive than women to financial incentives, irrespective of the network setting. Whether they work in isolation, in a recursive or a simultaneous setting, a given increase in financial reward will translate into more pronounced productivity gains. Likewise, the more potentially competitive the social environment, the more productive they are. Women behave entirely differently. In a recursive setting, they are sensitive to the productivity of their peers but to a lesser extent than men. In the more competitive simultaneous setting, women behave as though peer performances were irrelevant. They willingly ignore the information and behave almost as if they played in isolation. Put simply, men seem to thrive on competition even when monetary incentives are based on individual performance whereas women seem to refuse to play a competitiveness game.

We acknowledge that laboratory experiments have their own limitations. First, the task that must be accomplished and the environment in which it is performed is usually not representative of any real life situation. Second, networks are formed artificially for the sake of the experiment and may lack external validity. Indeed, in real life situations workers know their peers and the relative influence of each one need not be the same. Finally, in the context of the simultaneous treatment, our experimental design cannot discriminate between a pure rivalry effect (observing peers) and an image effect (being observed by peers). However, experimental evidence suggests the rivalry effect most likely dominates (Georganas et al., 2013). Our results nevertheless highlight the fact that men and women appear to behave differently in a network setting. Because most workers operate in such a setting, more research on this topic is certainly called for. 


\section{References}

Akerlof, G. A., 1982. Labor contracts as partial gift exchange. The Quarterly Journal of Economics 97 (4), 543-569.

Azmat, G., Iriberri, N., August 2010. The importance of relative performance feedback information: Evidence from a natural experiment using high school students. Journal of Public Economics 94 (7-8), 435-452.

Bandiera, O., Barankay, I., Rasul, I., 2005. Social preferences and the response to incentives: Evidence from personnel data. The Quarterly Journal of Economics 120 (3), 917-962.

Bandiera, O., Barankay, I., Rasul, I., 2009. Social connections and incentives in the workplace: Evidence from personnel data. Econometrica 77 (4), 1047-1094.

Bandiera, O., Barankay, I., Rasul, I., 2010. Social incentives in the workplace. Review of Economic Studies 77 (2), 417-458.

Barankay, I., 2012. Rank incentives: Evidence from a randomized workplace experiment. Wharton School, University of Pennsylvania.

Bellemare, C., Lepage, P., Shearer, B., January 2010. Peer pressure, incentives, and gender: An experimental analysis of motivation in the workplace. Labour Economics 17 (1), 276 283.

Bertrand, M., Luttmer, E. F. P., Mullainathan, S., August 2000. Network effects and welfare cultures. The Quarterly Journal of Economics 115 (3), 1019-1055.

Blanes i Vidal, J., Nossol, M., 2011. Tournaments without prizes: Evidence from personnel records. Management science 57 (10), 1721-1736.

Blume, L. E., Vienna, I., Brock, W. A., Durlauf, S. N., Jayaraman, R., ESMT, B., 2011. Linear social network models. Tech. rep., mimeo, University of Wisconsin.

Bramoullé, Y., Djebbari, H., Fortin, B., 2009. Identification of peer effects through social networks. Journal of econometrics 150 (1), 41-55.

Brock, W. A., Durlauf, S. N., December 2001. Interactions-based models. In: Heckman, J., Leamer, E. (Eds.), Handbook of Econometrics. Vol. 5 of Handbook of Econometrics. Elsevier, Ch. 54, pp. 3297-3380.

Browne, K. R., 2002. Biology at work: Rethinking sexual equality. New-Brunswick: Rutgers University Press.

Calvó-Armengol, A., Patacchini, E., Zenou, Y., 2009. Peer effects and social networks in education. Review of Economic Studies 76 (4), 1239-1267. 
Cassar, A., 2007. Coordination and cooperation in local, random and small world networks: Experimental evidence. Games and Economic Behavior 58 (2), 209-230.

Chen, Y., Harper, F. M., Konstan, J., Xin Li, S., 2010. Social comparisons and contributions to online communities: A field experiment on movielens. The American Economic Review 100 (4), 1358-1398.

De Weerdt, J., Dercon, S., 2006. Risk-sharing networks and insurance against illness. Journal of Development Economics 81 (2), 337-356.

Dickinson, D. L., 1999. An experimental examination of labor supply and work intensities. Journal of Labor Economics 17 (4), 638-670.

Dohmen, T., Falk, A., Fliessbach, K., Sunde, U., Weber, B., 2011. Relative versus absolute income, joy of winning, and gender: Brain imaging evidence. Journal of Public Economics 95 (3), 279-285.

Else-Quest, N. M., Hyde, J. S., Linn, M. C., 2010. Cross-national patterns of gender differences in mathematics: A meta-analysis. Psychological bulletin 136 (1), 103.

Falk, A., Ichino, A., 2006. Clean evidence on peer effects. Journal of Labor Economics $24(1), 39-57$.

Fischbacher, U., 2007. Z-tree: Zurich toolbox for ready-made economic experiments. Experimental Economics 10 (2), 171-178.

Fortin, B., Lacroix, G., Villeval, M. C., 2007. Tax evasion and social interactions. Journal of Public Economics 91 (11), 2089-2112.

Georganas, S., Tonin, M., Vlassopoulos, M., 2013. Peer pressure and productivity: The role of observing and being observed. Tech. rep., mimeo.

Gill, D., Prowse, V., 2012. A structural analysis of disappointment aversion in a real effort competition. The American Economic Review 102 (1), 469-503.

Gneezy, U., Niederle, M., Rustichini, A., 2003. Performance in competitive environments: Gender differences. The Quarterly Journal of Economics 118 (3), 1049-1074.

Goldsmith-Pinkham, P., Imbens, G. W., 2012. Social networks and the identification of peer effects. mimeo.

Greiner, B., 2004. An online recruitment system for economic experiments. MPRA paper, University Library of Munich, Germany.

Grodner, A., Kniesner, T. J., Bishop, J. A., 2010. Social interactions in the labor market. Foundations and Trends in Microeconomics 6 (4), 265-366. 
Guryan, J., Kroft, K., Notowidigdo, M. J., October 2009. Peer effects in the workplace: Evidence from random groupings in professional golf tournaments. American Economic Journal: Applied Economics 1 (4), 34-68.

Heckman, J., 1974. Shadow prices, market wages, and labor supply. Econometrica 42 (4), pp. 679-694.

Jackson, M. O., 2010. Social and economic networks. Princeton University Press.

Jackson, M. O., 2011. An overview of social networks and economic applications. The Handbook of Social Economics., ed. Jess Benhabib, Alberto Bisin and Matthew O. Jackson. Elsevier Press.

Kanasawa, S., 2005. Is "discrimination" necessary to explain the sex gap in earnings? Journal of Economic Psychology 26, 269-287.

Kandel, E., Lazear, E. P., 1992. Peer pressure and partnerships. Journal of Political Economy, 801-817.

Karlan, D., Möbius, M., Rosenblat, T., Szeidl, A., 2009. Trust and social collateral. The Quarterly Journal of Economics 124 (3), 1307-1361.

Laschever, R., 2011. The doughboys networks: Social interactions and labor market outcomes of World War I veterans. mimeo.

Lee, L.-f., 2007. Identification and estimation of econometric models with group interactions, contextual factors and fixed effects. Journal of Econometrics 140 (2), 333-374.

Manski, C. F., 1993. Identification of endogenous social effects: The reflection problem. The Review of Economic Studies 60 (3), 531-542.

Mas, A., Moretti, E., 2009. Peers at work. American Economic Review 99 (1), 112-45.

Möbius, M. M., Niehaus, M., Rosenblat, T. S., 2011. Managing self-confidence : Theory and experimental evidence. NBER WP 17014.

Munshi, K., 2010. Labor and Credit Networks in Developing Economies. Handbook of Social Economics. Elsevier Science, Ch. 23, pp. 1223-1254.

Niederle, M., Vesterlund, L., 2007. Do women shy away from competition? Do men compete too much? The Quarterly Journal of Economics 122 (3), 1067-1101.

Paarsch, H. J., Shearer, B. S., 2007. Do women react differently to incentives? Evidence from experimental data and payroll records. European Economic Review 51 (7), 1682 1707. 
Patacchini, E., Zenou, Y., 2008. The strength of weak ties in crime. European Economic Review 52 (2), 209-236.

Ray Li, C.-s., Huang, C.-Y., yu Lin, W., Sun, C.-W. V., 2007. Gender diffferences in punishment and reward sensitivity in a sample of taiwanese college students. Personality and Individual Differences 43, 475-483.

Sacerdote, B., 2001. Peer effects with random assignment: Results for Dartmouth roommates. The Quarterly Journal of Economics 116 (2), 681-704.

Stern, N., 1986. On the specification of labour supply functions. Unemployment, search and labour supply. Cambridge University Press, pp. 143-189.

Stinebrickner, R., Stinebrickner, T. R., 2006. What can be learned about peer effects using college roommates? Evidence from new survey data and students from disadvantaged backgrounds. Journal of Public Economics 90 (8), 1435-1454.

Topa, G., 2011. Chapter 22 - Labor markets and referrals. In: Jess Benhabib, A. B., Jackson, M. O. (Eds.), Handbook of Social Economics. Vol. 1 of Handbook of Social Economics. North-Holland, pp. 1193 - 1221.

Torrubia, R., Avilab, A., Moltob, J., Caserasa, X., 2001. The sensitivity to punishment and sensitivity to reward questionnaire (SPSRQ) as a measure of Gray's anxiety and impulsivity dimension. Personality and Individual Differences 31, 837-862.

Wei, W., Lu, H., Zhao, H., Chen, C., Dong, Q., Zhou, X., 2012. Gender differences in children's arithmetic performance are accounted for by gender differences in language abilities. Psychological science 23 (3), 320-330. 


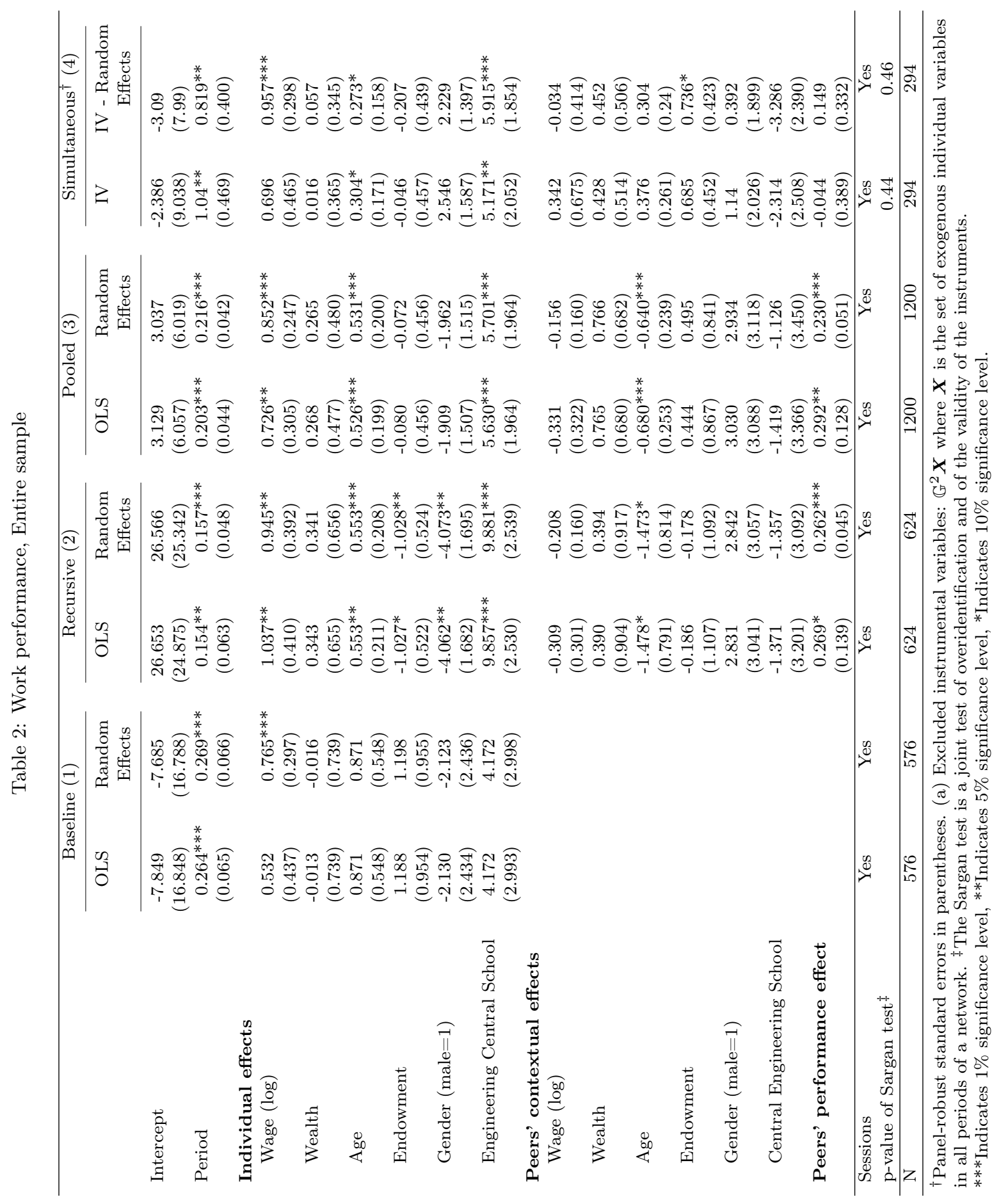




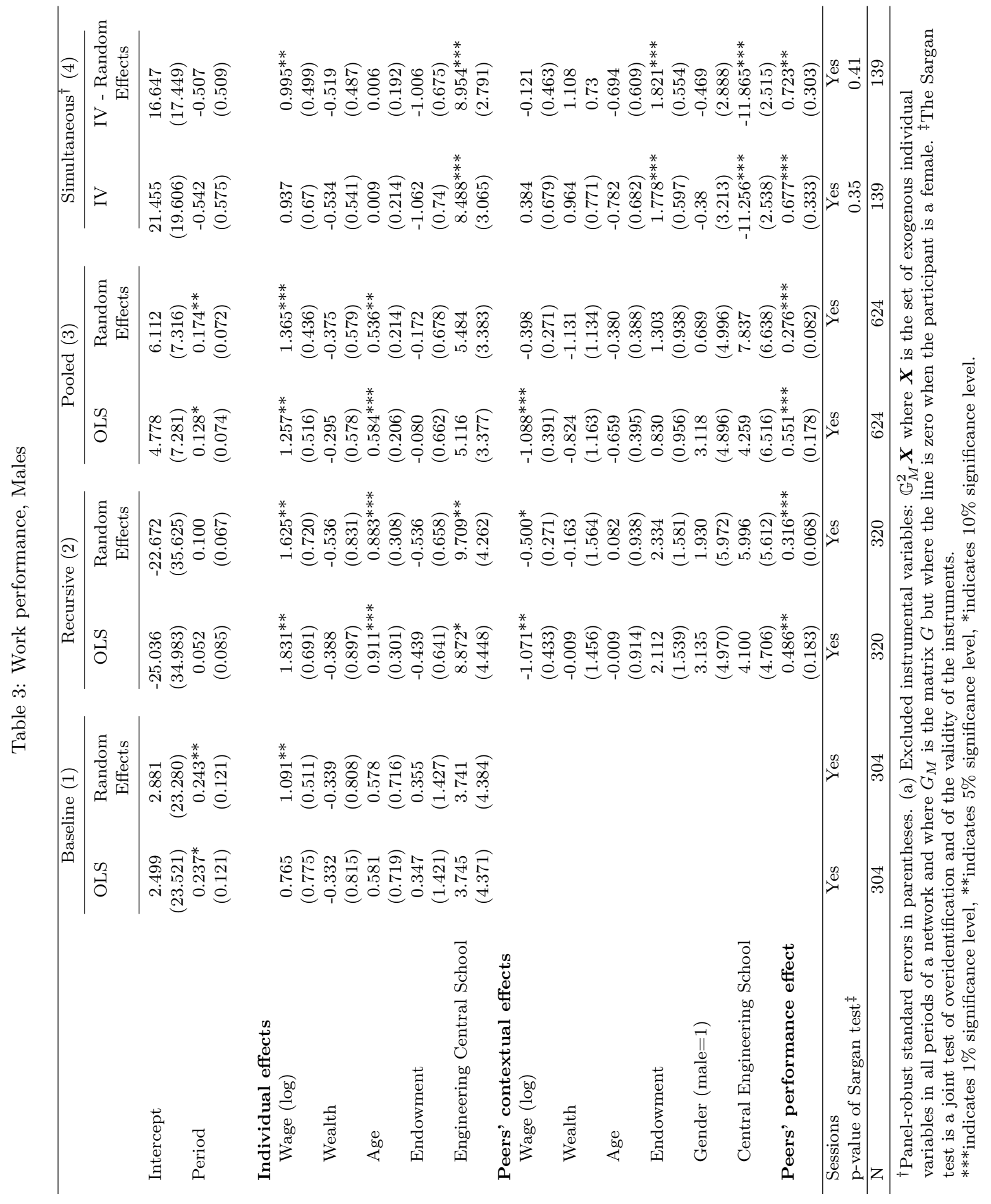




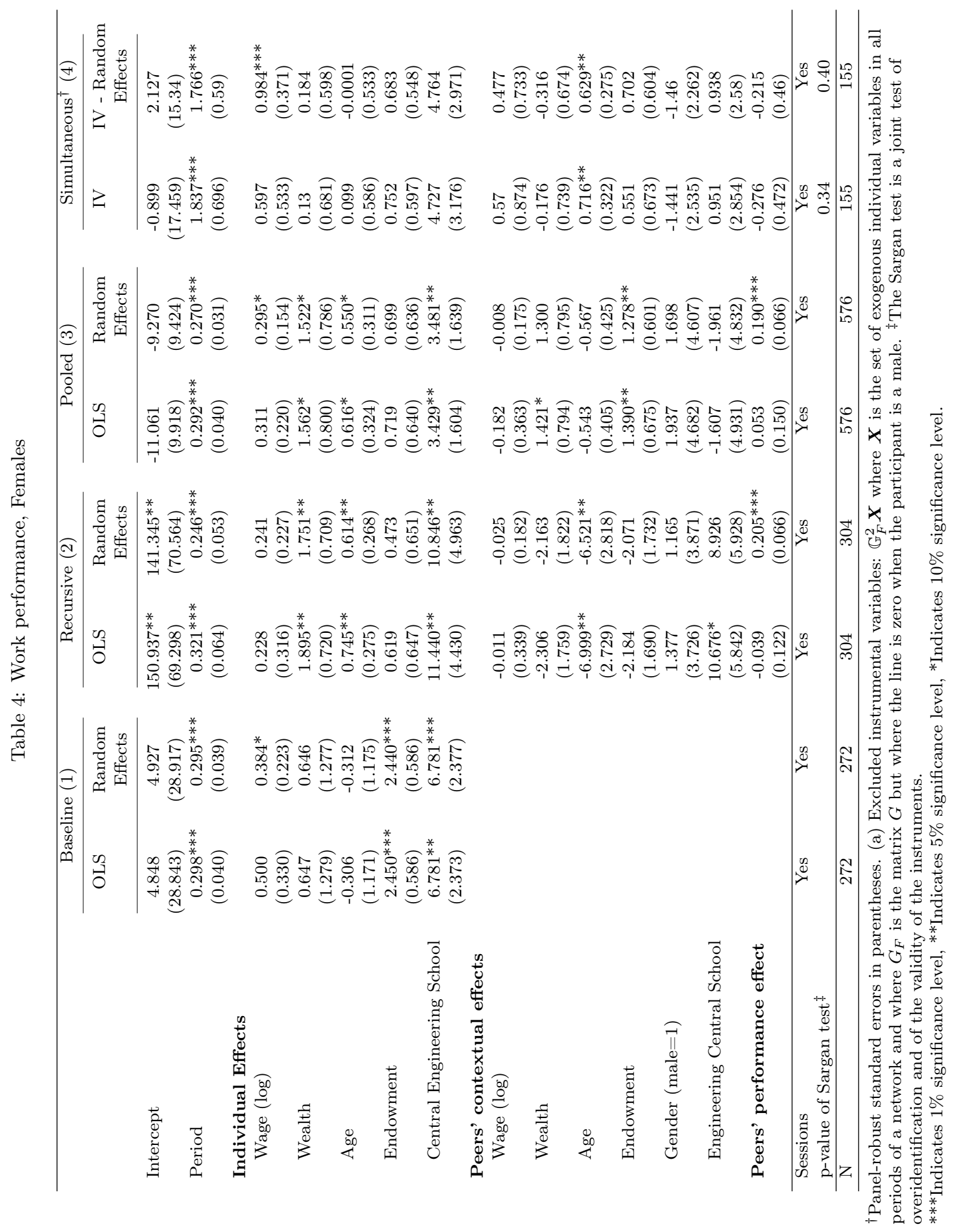




\section{Appendix A. Tables}

Table A.1: Characteristics of the experimental sessions

\begin{tabular}{ccc}
\hline Session number & Number of participants & Treatments \\
1 & 18 & Baseline \\
2 & 18 & Baseline \\
3 & 18 & Recursive \\
4 & 12 & Recursive \\
5 & 9 & Recursive \\
21 & 18 & Simultaneous \\
22 & 18 & Simultaneous \\
23 & 12 & Simultaneous \\
24 & 12 & Simultaneous \\
25 & 18 & Simultaneous \\
26 & 18 & Simultaneous \\
27 & 18 & Simultaneous \\
\hline TOTAL & 189 & \\
\hline
\end{tabular}

\section{Appendix B. Instructions for the Simultaneous treatment}

(Other instructions available upon request) We thank you for participating in this experiment on economic decision-making. The session consists of 4 periods, each divided into several rounds during which you will be able to perform a task, as described in detail below.

One of these rounds will be randomly selected at the end of the session to determine your earnings in Euros. Your earnings in Euros depend on your performance during this round. Moreover, you will receive an initial endowment for the whole session. The amount of this endowment will be randomly selected among the following values: 2, 4 or 6 Euros. You will be informed on the amount of this endowment for the session before starting the first period.

Your earnings will be paid to you in cash and in private in a separate room. During the session, you will be matched with one or two participants, names "peers" in the rest of these instructions. You will keep the same peers throughout the experiment. You will never know their identity.

At the beginning of the session, you will be asked a few personal questions (gender, age, relative wealth of your family compared to the other students). Then, you will be informed on your peer's answers to these questions. If you have two peers, you will be informed of their mean answers to the questions about their age and the relative wealth of their family. "Men" indicates that your two peers are men; "women" indicates that your two peers are women; "mixed" indicates that one peer is a man and the other peer is a woman.

You will be also informed on the initial endowment of your peer or the average initial endowments of your two peers for the session. All your decisions during the session will remain anonymous. You will never have to enter your name in the computer.

\section{Description of each period}

Each of the four periods consists of several rounds. The number of rounds can change across periods. Each round lasts 2 minutes 30. During these 2 minutes 30, you are invited to perform the following task. 
This task consists of multiplying two-digit numbers by one-digit numbers that are displayed on your screen (for example, $15 \times 3,22 \times 7$ ). You must enter a value in the corresponding box and submit your answer by clicking the "validate" button. You must make these calculations in your head. It is strictly forbidden to use a pen, a calculator, a mobile phone or any device to multiply the numbers, otherwise you will be immediately excluded from the session and the payoffs. One you have submitted an answer:

- If this answer is not correct, a message will inform you and you will be able to enter a new answer. Only a correct answer will make another multiplication appear.

- If this answer is correct, your score is increased by one unit and a new multiplication is displayed on your screen.

You can make as many multiplications as you like during each round. You are also allowed to read the magazines that are available on your desk.

Please note that before the beginning of the first period, a practice round of 2 minutes 30 will allow you to train at the task. Your performance during this round will be count for the determination of your earnings.

\section{Determination of your earnings}

Your earnings during this experiment depend on your piece-rate and your score (your number of correct answers) in a round of a period randomly drawn by the computer program at the end of the session. Your piece-rate for each correct answer is randomly selected at the beginning of each period. It can change across periods. In contrast, it remains constant across the rounds of a same period.

This piece-rate for each correct answer can take the following values: $€ 0.10, € 0.50, € 1$. Your earnings for the experiment are therefore calculated as follows:

Your total earnings $=$ your initial endowment + (your piece-rate $\times$ your score in the randomly selected round). The incorrect answers are not accounted for in the determination of your earnings.

\section{Information}

At the beginning of the first round of each period, you are informed on the piece-rate for the period. You are also informed of the piece-rate of your peer in the same period. If you have two peers, you are informed on their average piece-rate. Indeed, your peers can receive different piece-rates than yours during a period. Their piece-rate is also randomly selected among the following values: $€ 0.10$, $€ 0.50, € 1$. Note that the piece-rate of the other participants in this session in a given period can also differ from your piece-rate.

At the end of each round, you are also informed on your peer's final score in the round for his piece-rate in the period; if you have two peers, you are informed on the mean final score in this round. Please note that your peer or your peers had to solve exactly the same multiplications as you and in the same order as you during each round. Similarly, all the participants in the session have to solve the same multiplications and in the same order as you in each round.

You are permanently informed on your current score in the round and on the time remaining until the end of the round. At the end of each round, your final score in the round is displayed, as well as a reminder of your piece-rate for the period, your peer's piece-rate and final score or your two peers' average piece-rate and average final score.

You can find below a copy of the screenshot during the task. The numbers indicated are only an example.

To sum up: 
- Each of the four periods consists of several rounds during which you can solve multiplication problems.

- From one period to the next, you keep the same peer or the same two peers. The piece-rates are randomly determined.

- During a period, you keep the same piece-rate across rounds.

- From one round to the next, the multiplications are modified randomly. Your peer or your peers receive the same multiplications problems and in the same order than you.

- You are informed at the beginning of the period on your peer's piece-rate or on the average piece-rate of your two peers.

- At the end of each round, you are informed on your final score and your potential earnings for this round, and on your peer's score or on the average score of your two peers. You are reminded your piece-rate and your peer's piece-rate or the average piece-rate of your two peers.

Please read again these instructions and answer the questions on the questionnaire that has been distributed to you. If you have any question, please raise your hand and we will answer to your questions in private. Once we will have answered your questions, a questionnaire will be displayed on your computer screen. Then the practice period will start. The following periods will start automatically. At the end of eh session, you will be invited to fill out a final questionnaire.

You are not allowed to communicate with any other participant. 